\title{
Dimensions of Authenticity in Malay Cuisine from Experts' Perspectives
}

\author{
Humairah Hamzah ${ }^{1}$ \\ Muhammad Shahrim Ab Karim ${ }^{1}$ \\ Mohiddin Othman ${ }^{1}$ \\ Azimi Hamzah ${ }^{2}$ \\ ${ }^{1}$ Department of Food Service \& Management, Faculty of Food Science and Technology \\ Institute of Social Science Research (IPSAS), Putra- InfoPort \\ Universiti Putra Malaysia, 43400 UPM Sedang, Selangor Malaysia
}

\section{Doi:10.5901/ajis.2013.v2n3p369}

\section{Abstract}

Food authenticity is defined as the originality and genuine of Malay cuisine in various aspects. It is an important element in portraying the family identity, culture and heritage of Malay community in Malaysia. Food experts including professional chefs and cooks are believed the parties that still practising and maintaining the authenticity of Malay cuisine in today's scenario. Hence, in-depth interviews were individually conducted among the Malay food experts $(n=15)$ in each State in Peninsular Malaysia to seek how an experts interprets the meaning and characteristics of authenticity in Malay cuisine that influenced the taste of the food. Technically, the food experts were chosen based on the diverse understanding, skills and experiences in Malay cuisine. Furthermore, the interview data were strengthened with extensive observation in their food outlets. Consequently, data analysis by using a self determination theory approach revealed that Malay food experts' personality and motivation were directly accessed them to view the authenticity of Malay cuisine in three dimensions. There were consists of family culture (relational orientation, value, cooking skill, cooking method, cooking utensil and cooking ingredients), self interest (hobby, passion, permanent job, financial and events), and awareness (authentic taste, texture and appearance, modification, and alteration) characteristics. In a nutshell, these empirical findings demonstrated how a model of dimensions of authenticity in Malay cuisine and the characteristics able to influence the authentic taste of the cuisine from the experts' perspective and served as guidance for future researches and interventions in Malay cuisine authenticity.

Keywords: authenticity; Malay cuisine; food expert; family culture; cooking skill; authentic taste

\section{Introduction}

Malays in Peninsular Malaysia is reffering to various sub-ethnic groups such as Malays Kelantan, Minang, Jawa and Bugis which are believed to have different family origins based on their migrations. According to Hatin, et al. (2011) they speak Malayo-Polynesian language which is a member of the Autronesioan family. As the consequence of the melting pot effect, Malay culture is also has absorbed the influence of Chinese, Indians, Siamese/Thai, and Arab by their exitence centuries ago through traders (Comas, et al., 1998). Since that Malays in Malaysia has evolved and offer a very unique culture with the trace of many ethnic groups influence to be inherited. This culture and historical knowledge should be preserved and passed down to other generation. All this while it is being passing down by the way of oral tradition. The growth of cultural tourism through revitalization of cultural traditions somehow give life to the heritage product. However, we should be alarmed that the efforts to develop a national culture might be resulting a synthetic fision and neglecting the authenticity framework.

Natural resources that are readily available in this country allows the creation of a vast array of flavourful, delicious, unique and authentic cuisines. According to Kolar \& Zabkar (2010) and Yeoman, Brass, \& Mcmohan-Beattie (2007) the elements of authenticity are important for strategies in marketing product especially in heritage tourism because it is explanation the concept of authenticity in particular interest.While in an article by Olsen(2002), the authenticity considered as a value, a motivational force (Cohen,1988; Naoi, 2004; Leigh, Peters, \& Shelton, 2006), a 'claim' or belonging (Peterson, 2005), a perception (Cohen,1988), and the preference group make (Reisinger \& Steiner, 2006). The advantage of authenticity are serving a means of preservation and promotion. While in culinary, genuine cuisine will get true representations of Malaysian ethnic culture and the practitioners will be able to sustain their heritage 
Each ethnic culture can be seen through the way of speech, traditional clothing and the most obvious is through the cuisine or food. Md. Nor, et al. (2012) study has had a profound influence on food is midpoint of culture identity through the ethnicity and some elements of food preparation and consumption are the part of identity. Where by Powell (2007) revealed that food preparation and consumtion are related to identy of community, age, ethnicity, gender, locale, occupation and religion. While there is an argument that mentioned preparation and consumption are closely related to cultural of the foods, tools and utensils, techniques and ingredients used in preparing the cuisine and as their customs to understand culture and ethnic identity (Verbeke \& Lopez, 2005; Vu, 2009; Md.Nor, et al., 2012). Therefore the statement "we are what we eat" it really reflects of the origin and ethnic of the society.

\section{Methodology}

\subsection{The literature review}

As a person the capacity for responsible actions, a natural aspiration to learning and understanding things, and the desire to do good job reveal what the expert confess in culinary. As an empirically based theory of human motivation, Selfdetermination Theory (SDT) addresses several basic issues associated with cognitive, affective and psycho-motor development (Ankli \& Palliam, 2012). Perception of the self, one's psychological and emotional needs, life goals and aspiration, individual dynamism, culture and the impact of social environments are key issues that determine one's ability to self actualize which is the focus in SDT that represent for this study is the dimensions of authenticity in Malay cuisine from expert's perspectives. Base on Deci \& Ryan (1985;1991) the founder of SDT, it is focuses on the social-contextual conditions that facilitate the nature processes of human motivation or self-motivation. Inside handbook of SDT 2002, Deci and Ryan present SDT as a theory of personality development and as a theory of self motivated behavior change. Base on the study done by (Gagne \& Deci, 2005) SDT is a prosesses through extrinsic (based in importance) and intrinsic (based in interest) motivation and both related to performance, satisfaction, trust, and well-being in the workplace. Thus, this study will impliment the theory base on the culinary field.

Various study has shown that perceptions of food products and services as authentic elevates its value in the eyes of the consumer. In fact the search for authenticity is an expectation for something genuine through appearance and interpretation in existential philosophy, in which it is considered to be the ability and willingness of the individual to live true on their nature and culture. Thus, research done by Goldman (1992) about cooking, the colonialism will maintains the cultural authority in texts such as cookbooks, memoirs, and novels illustrate the conscious and unconscious of "the self". Their opinion towards authentic cuisine is not only implies the existence of inauthentic food, but reveals the ubiquity of self-assertions that affirm and appropriate the cultural expressions of people from different ethnic backgrounds. This authenticity has strong significant relations between implicit and explicit of the cultural and ethnic. Where by Abarca (2004) also mentioned that the authenticity of the cuisine are based on the genuine of the food and rooted in cultural and socio-economic are the real attitudes and implications certain ethnic group. Therefore, the important of authenticity for the cuisine is it can contributes to the cooking process and can preservation of the ethnic identities and culture. In reality the terms of authenticity in each cuisine are given by the community and it is confirm by the expert through the ingredients, methods, cooking styles and taste.

Malay culture enriched with its unique lifestyles of people and customs, traditional cuisines, traditional attire, traditional music and dance, games and pastime, architectural heritage, handicrafts, museums, handicrafts centers and major heritage sites. The true experience of Malay culture is incomplete without a taste of authentic cuisine because culture is a system of shared understandings that shapes by experience and provides meaning to a set of rules for behaviour (Caprio, et al., 2008). Each state has its local specialties but rice is a unifying element in every meal, a generous, steaming helping of it, accompanied by a selection of dishes or lauk, including fish, poultry, meat, vegetables, ulaman and sambal. Beside Malay cuisine usually served all at once, without order meals like in western culture. Malay cuisines represent fresh ingredients, variety of spices and some of the ingredients are unique and healthy. Information about healthy cuisine sometimes has a positive effect on liking (Eertmans, Baeyens, \& Van den Bergh, 2001).

\subsection{Design and Sample}

For a theoretical interpretation of experienced realities a grounded theory approach are used based on themes that emerged from the data (Bowen \& Devine, 2011; Strauss \& Corbin, 1998) was taken in this qualitative study in order to understand the dimensions of Authenticity in Malay cuisine. Base on initial coding it will breaking down the qualitative 
data into discrete parts, closely examining them, and comparing them for similarities and differences (Saldana, 2009; Strauss \& Corbin, 1998). It is a starting point to provide this study with analytic leads for further exploration. Strauss \& Corbin, (1998) advice that at least ten interviews or observations with detailed coding are necessary especially for building a grounded theory.

In order to develop individual and in-depth information of the views of authenticity and knowledge providers on the dimensions in Malay cuisine associated with personality and motivation, semi-structured interviews were employed with open-ended questions are developed in advance, along with prepared probes. Unplanned, unanticipated probes also are used. Probes used for clarification the answers from the interviewee. The semi-structured approach will encourage good interaction between interviewer and interviewee. Interviewer are asking the experts base on their personality and motivation to read the target's story and determine their memory, emotion and feeling towards Malay cuisine. Interviewer will ask the same questions of all of the participants, but not necessarily in the same order, supplementing the main questions with either planned or unplanned probes. A maximum of 30 seconds were allowed for giving each valid association. The interviews are voice-recorded and transcribed in preparation for analysis. According to Schmitt (1998), every valid words bring out by each participant were retained for data analysis.

The participants were selected within each state using a convenient intentional and reasoned sampling with predetermined quotas (Guerrero, et al., 2010). Convenience sampling is frequently used in behavioural science research (Graveter \& Forzano, 2008; Guerrero, et al., 2010) and exploratory research where researcher are interested in getting information in a specific topic through involving participants who meet specific criteria that are relevance to the study. In this study, the participants are an expert in authentic Malay cuisine and ought to be Malay with more than ten years experiences in this culinary field and still practice. The selections of the participant are base on their experience, their foundation, and vast knowledge about the cuisine including cuisine from others district or province. There are two participants each in Kelantan, Selangor and Johor due to high Malay populated in that state base on Malaysia Statistic Department (2010). Out of $(n=15)$ participants, 6 of them are male and balances are female. Participant criteria and the distribution are summarized in Table 1.

Table 1: Distribution of in-depth interview participants in Peninsular Malaysia

\begin{tabular}{|l|c|c|}
\hline Participants Criteria & States & $n$ \\
\hline - At least 10 years working experience in preparing & Perlis & 1 \\
\cline { 2 - 3 } traditional Malay cuisine and they still practice. & Kedah & 1 \\
\cline { 2 - 3 } - Very competent, knowledgeable and deep & Pulau Pinang & 1 \\
\cline { 2 - 3 } understanding about the cuisine. & Perak & 1 \\
\cline { 2 - 3 } - Owner/working as a Malay chef/cook at restaurant & Kelantan & 2 \\
\cline { 2 - 3 } or caterer or cafeteria. (Senior rank) & Terengganu & 1 \\
\cline { 2 - 3 } - Skill full in preparing authentic Malay cuisine. & Pahang & 1 \\
\cline { 2 - 3 } - Represented a variety of capability including broad & Johor & 2 \\
\cline { 2 - 3 } understanding in Malay cuisine. & Melaka & 1 \\
\cline { 2 - 3 } - Diversity of origin and geographical background & Negeri Sembilan & 1 \\
\cline { 2 - 3 } & Selangor & 2 \\
\cline { 2 - 3 } & Kuala Lumpur & 1 \\
\hline & 12 & 15 \\
\hline
\end{tabular}

\subsection{Data Analysis}

Data collection was conducted from 2012 to 2013, included in-depth interviews as well as extensive participant observation (Bogdwic, 1999). Base on the observations it suggest that authenticity is an important measure in determining the quality of the cuisine. It also show that authenticity requires more than just ingredients, recipes or the menus but the atmosphere and ambiance also play a rule. A semi-structured interview guide was pilot tested with Malay chef in Klang Valley. Initial interviews ranged from 45 to 90 minutes. The questions are base on background, family history, cultural customs food, cooking experience and authenticity. Demographic information reported by the experts provided context for the interviews and including age, birthplace, ethnic identity, education and employment. Interviewer were doing four follow-up interview to reconfirm the statement that participant made. This follow-up interview as a form of member checks on the trustworthiness of the information (Lincoln \& Guba, 1985). The words draw in each interviews were first translated to English and then entered into an excel file template. A back-translation process (Brislin, 1970; 
Maneesriwongul \& Dixon, 2004; Guerrero et al., 2010) was applied for those words difficult to translate from Malay words.

Thematic analysis is an analysis of qualitative data through the use of extended phrases and/or sentences rather than shorter codes (Auerbach \& Silverstein, 2003; Boyatzis, 1998). This analysis was employed to identify the key element of authenticity in Malay cuisine in Peninsular Malaysia. Themes and codes were developed empirically through the breakdown of the data generated in the interviews. With regard to synonymous with inductive analysis; Mason's (2002) posited approach thus accounts for the way in which the research process moved back and forth between analysis and the development of theory, detailing themes and constructing codes relating to knowledge adoption from both the interview data, and the literature review. The result has been the development of personality and motivation approaches, designed to guide and interpret researcher on new issues across family culture, self-interest and awareness processes in preparing authentic Malay cuisines.

\subsection{The validity of the data}

Validity is a measure of how well variables could forecast a result by utilizing the information gathered from other could forecast a result by utilizing the information gathered from other variables (Bordens \& Abbott, 2005) and will measure consistently to provide similar results (Bordens \& Abbott, 2005). A few techniques that might be utilised by qualitative researchers in order to demonstrate the 'trustworthiness' of the analysis and were embrace all through (Lincoln and Guba (1985). The technique of 'member-checking'; interpretations and conclusions were thoroughly tested with those who participated in the study. According to Fereday and Muir-Cochrane (2006) for transparent 'illustration', interpretive rigour is used to achieved through the use of verbatim quotations; an approach which accords with the request. The positive responses received from respondents after assessing the study's findings, combined and the direct reflections of the participants in the reporting of the analysis, thus add a level of 'content/face validity' to the themes. Beside that to establishing the validity through this study, author employ five people who are related in this culinary field member checking to get very thick description towards the data.

\section{Results and Discussion}

Out of $n=15$, the first themes has reveal under the dimensions of authenticity in Malay cuisine are family culture followed by self-interest and awareness. Culture is a dynamic construct in shared understandings change over time as they are shaped or informed by the experience of individual or the entire family group (Caprio, et al., 2008). Cuisine is an expression of cultural identity and a means of preserving family and community unity. Whether taken as product or practice, chef or consumer, or everyone and everything in between, cuisine acts as a vital agent of socialization. Cuisine reaches beyond the food that supplies its raw materials; it outperforms the chef or cooks by whom it is produced; it outshines even the consumers who justify the cycle of production. All this is possible because cuisine is not merely a culinary code that anchors custom.

According to Salleh (2006) family and kinship linkages are significant in the life of the Malays, and reinforce their values, norms and cultural identity. For examples, the senior generation are always accorded respect by the younger generation. This behaviour is extended to other members of the community of the same generational levels. The senior members would reciprocate by displaying moral concern for the younger members but now the interpersonal interactions have changed under the pressure of changing social, religious and economic circumstances. Research on family decision-making (Foxman, Tansuhaj, \& Ekstrom, 1989) has shown that the family is the most important social group to influence the decision-making process of individual members (e.g., children, adolescents and parents). This is also the case concerning food choice and consumption (Olsen \& Ruiz, 2008; Tuu et al., 2008). A few previous studies extend the traditional theories of planned behaviour (Ajzen, 1991) and suggest that social identity should be included in the models as a moderator in the norm- behaviour relationships (Terry \& Hogg, 1996; Wellen, Hogg, \& Terry, 1998). Therefore, this study integrates family identity as a moderator for the effects of family norm on food choice.

Cuisine place culinary practices in a social context by sharing the experience of taste in an idiom that allows articulation of the present and reproduction in the future. Cuisine specifies the conditions between the general and the particular as it negotiates the gap between collective taste and idiosyncratic tastes. Above all, by socializing appetite and taste, cuisine turns the individual relationship with food into a collective bond. These remarks show the cuisines consume abides by a standard of authenticity that adheres to particular aesthetics, menu items, and ingredients. According to Tuchman and Levine (1992), the inevitable "naturalness" of products related to specific ethnic traditions is often associated with the created character of ethnicity. Food and drink though, is expressive of region, community, and its 
culture or a place remote in time. Hughes (1995) suggested that "associating dish/ingredient with a specific place, using local/colloquial terminology, associations with personalities, real or fictional, use and promotion of 'naturalized' ingredients and reference to miscellaneous historical or fictional events" (p.784) are strategies by which regions, communities and cultures might appropriate food and drink to elevate perceptions of product authenticity.

All the participant mention and agreed that authenticity is a kind of originality, truth, genuine and traditional to get the cook the food becomes so truth are usually complex. It is nature as human beings there prefer complexity. As Malay the everyday food is perhaps better-quality, in terms of the freshness of the ingredients, the nutrition and the actual method and cooking, compare to process food. All species, apparently, exercise their sense of taste: as long as food supplies are more or less adequate, no creature eats the whole range of foods that are available to it and potentially nourishing. A key factor of success is awareness and recognition of other members of our own species and why the decision to include inauthentic ingredients. There are instinctive elements that religious instinct: the need for security and guidance in life; the need to belong to a group, but culture is surely much stronger.

Another key dimension of authenticity resides with the individual. These 'personal' factors (Kuznesof et al., 1997) include the cultural awareness and knowledge of the consumers. Personal factors might emerge as an individual connection between the produced and the consumed, which may be based on ethnicity for example (Johnston \& Baumann, 2010) or simply the contemplative process (Beer, 2008) so the food just tastes 'right'. Perceived authenticity depends much on self-identity-personality, personal goals, life style and values-as revealed by marketing research from the retail domain (Camus, 2004). Regardless, as Johnston and Baumann (2010) emphasise, authenticity is a social construction, not inherent only to an individual or an object. Here, by who else (Beer, 2008), and where the food is consumed embodies authenticity, whether this be in the family home (Moisio et al., 2004), in a culturally ambient restaurant with a plethora of authenticity 'signifiers' (Lu \& Fine, 1995) or in a (merchant) precinct which communicates authenticity by a range of product signifiers other than food (Carroll \& Torfason, 2011).

The basic pattern of Malay cuisine lies in the preparation of 'wet' and 'dry' spices used to flavour the dish. The 'wet' spices include shallots, ginger, garlic, onion, fresh chillies, fresh turmeric, ginger, and traditionally pounded in mortar and pestle or noon as batu lesung. The 'dry' spices such as coriander, cumin, aniseed, cloves, cinnamon, black pepper, nutmeg, fennel and cardamom usually comes in two conditions, powder or whole spices. Malay curries or gulai are delicately flavoured with various herbs and leaves such as lemongrass, galangal, kaffir lime leaf/daun limau purut, coriander leaf, turmeric leaves, curry leaf, ocimum basilicum/daun kemangi, piper sarmentosus/daun kadok, pandan leaves/daun pandan and daun kesum. The ingredients use is slightly the same with other South East Country such as Thailand, Indonesia, Singapore, Vietnam and Filipina due to the roots of origin

Tradition without awareness of history and without possibility of change is mere stereotype, and innovation without consciousness of genealogy and situations is sheer experimentation. A national or cultural cuisine encompasses cooking traditions, practices, techniques, meal structure, flavours, ingredients, and dishes. Because a cuisine is comprised of so many interlocking components, authenticity can be questioned if one or more of those components is absent or altered. It is important to note, however, that what counts as "authentic" is highly subjective and can vary from person to person. Malay cuisine is characterized by a balance of hot, sour, salty, and sweet flavors. The proportions required to achieve this balance may vary from person to person, but without this balance, the food is considered inauthentic (Alford and Duguid 2000:12).

Ethnic groups vary from each other, often widely, by the cultural context of their food and diet. According to Guerrero et al. (2009), when defining a "traditional food product (TFP)," sensory parameters and identifying a particular taste are the best ways. Evaluation of the sensory attributes of foods is an easy and effective way to distinguish the authenticity of such products, as well as the culture related to it. The recognition of flavour is a direct link to flavour and memory. Consumers often have difficulty describing new foods and flavours because they must rely on memory and experience to do so, even though they have not tasted the product. "This inability to define, measure, or quantify taste may contribute to the link between memories and taste" (Varadachari, 2002). It is difficult to describe new foods or sensations without the prior memory of similar foods or sensations. Research has shown that young children are better able to remember a flavour if the flavour recalls positive memories about the time it was consumed. This is possibly due to the fact that they are better able to describe the flavour, engraining it in their memory for future references to repeated exposures (Lumeng and Cardinal, 2007).

Alternatively, Abarca (2004) argues, food can be reduced to two determinants: the authenticity of the cook and the authenticity of the process. What binds the process is the foodstuffs production, which for Kuznesof et al. (1997) represents the situational factors. On the one hand the authenticity of the production process is elevated by its methods simplicity and naturalness (Groves, 2001; Hughes, 1995; Johnston \& Baumann, 2010) and on the other being reflected in 
the small-scale or non-commercial characteristics of the producing organisation (Carroll \& Torfason, 2011; Johnston \& Baumann, 2010). The integrity of the cook too implies authenticity (Beer, 2008) as do celebrity status or product endorsement (Johnston \& Baumann, 2010).

There is a few sub-themes notice during analysing and transcribing the interview section. Table 2 show examples of the statement from the participant that related to family culture, self-interest and awareness.

Table 2: Examples of the statement from the participant

\begin{tabular}{|c|c|}
\hline Participants & Statements \\
\hline 4 & $\begin{array}{l}\text { "This restaurant I got from my father and it is a family business...our business is maintained but actually, we } \\
\text { struggle to protect the cuisine for future generations. That's why we believed in producing good quality of } \\
\text { foods are start from the raw ingredients and cooking method that gives good flavour and taste..." }\end{array}$ \\
\hline 7 & $\begin{array}{l}\text { "My cooking philosophy is based on the belief that great authentic cuisine is come from fresh ingredients } \\
\text { and cooking in a proper method. There is no short way in making authentic Malay cuisine. If you follow the } \\
\text { rule of cooking you will get better results and tastes". }\end{array}$ \\
\hline 9 & $\begin{array}{l}\text { "It is true that my favourite foods are those I grew up with, and I advise you to keep close to Malay roots } \\
\text { and preserve the food identity holds much wisdom. This cuisine would then become a means of preserving } \\
\text { a memory for the diner, as well as keeping the next generation in touch with authentic, Malay cuisine is } \\
\text { really about". }\end{array}$ \\
\hline 12 & $\begin{array}{l}\text { "Now, I saw Malay cuisines more adventures and diversity in the city. I am afraid they fail to see the } \\
\text { elements of authenticity on their cuisines. Not all customer know the food...I am feel so sorry for them if } \\
\text { they experience authentic cuisine but it not authentic because of modification and alteration... they call it as } \\
\text { fusion food". }\end{array}$ \\
\hline 3 & $\begin{array}{l}\text { "The most important part in authentic Malay cuisine is the taste. You must practice and practice until you } \\
\text { get hold the same taste of original recipes. I'm believed more work done by hand (referring to traditional } \\
\text { equipments and tools) is more authentic the cuisine. But now it seems not that relevant anymore because } \\
\text { of time consuming. People are busier and they need to use modern equipments or utensils to minimize time } \\
\text { during cooking". }\end{array}$ \\
\hline 11 & $\begin{array}{l}\text { "Teach your son or your daughter about our heritage food. If we don't show to them who else....let the } \\
\text { children feel more and more families with the cuisines, teach them how to cooking, show them the } \\
\text { ingredients, tell them the history of the cuisines and also the geography where there are came from". }\end{array}$ \\
\hline 15 & $\begin{array}{l}\text { "Malay cuisines are unique because we don't have standardized recipes. We as an experience chef and } \\
\text { cook believed on individual skill". }\end{array}$ \\
\hline 1 & $\begin{array}{l}\text { "I become as cook because I love cooking, but now this is my career....before this I am working with other } \\
\text { people and now I managed to open my own business. Passionate....that the key word, if you passion } \\
\text { enough with your job and Allah will reward you something such as you will good profit margin". }\end{array}$ \\
\hline 3 & $\begin{array}{l}\text { "...because of customer demand, sometimes I have to make small modification and alteration towards the } \\
\text { ingredients to suite my customer need and preferences. But I still try to maintain on the authentic taste of } \\
\text { the dishes. }\end{array}$ \\
\hline
\end{tabular}

\subsection{A model of Authenticity in Malay Cuisine from Experts' Perspectives}

A model of three dimensions of influence on authenticity in Malay cuisine emerged from the experts' perspectives: (1) the family culture, (2) the self-interest, and (3) the awareness shown in Figure 1. All three domains interacted to influence the dimensions of authenticity in Malay cuisines, though certain characteristics within domains emerged as more and less salient for experts' depending on their Malay food preparation. Characteristics that could influence most are base on the family cultures included relational orientation, value, cooking skill, cooking method, cooking utensil and cooking ingredients. Self-interest characteristic included insensitivity towards Malay events, cooking as hobby, cooking with passion, work as permanent job and lack of consideration for others towards financial. Awareness on the authentic taste, texture and appearance, modification, and alteration towards Malay cuisines were relevant to Malay culinary practitioners. The experts whose practice Malay culinary believe on the factor to show in the model that present of authenticity in Malay cuisine and perhaps other ethnic also. If they ignore one of the components the term authentic is not that relevant anymore.

To conserving the authenticity of the heritage cuisine, it should include the involving as many stakeholders as possible in helping to identify what makes a heritage from significant. It should engage with government and nongovernmental agencies. For example, those Malay food experts should work together with the ministry of heritage..... to 
establishing the ethical and effective methods of ensuring that the significance of a heritage Malay cuisine is safeguarded, including the continued practice and transmission of the food, even if in an altered format. It should engage with the relevant communities in practising, recording and documenting the recipes of the authentic cuisine and its changes over time. This will benefit to the community in reinforcing their identity because the broader community where possible in encouraging social co-operation within and between groups. It also can enhance the creative diversity of humanity and encourage the appreciation, use and enjoyment of food in this diversity (UNESCO 2001a: 5-6).

Figure 1. A model of Authenticity in Malay Cuisine from Experts' Perspectives

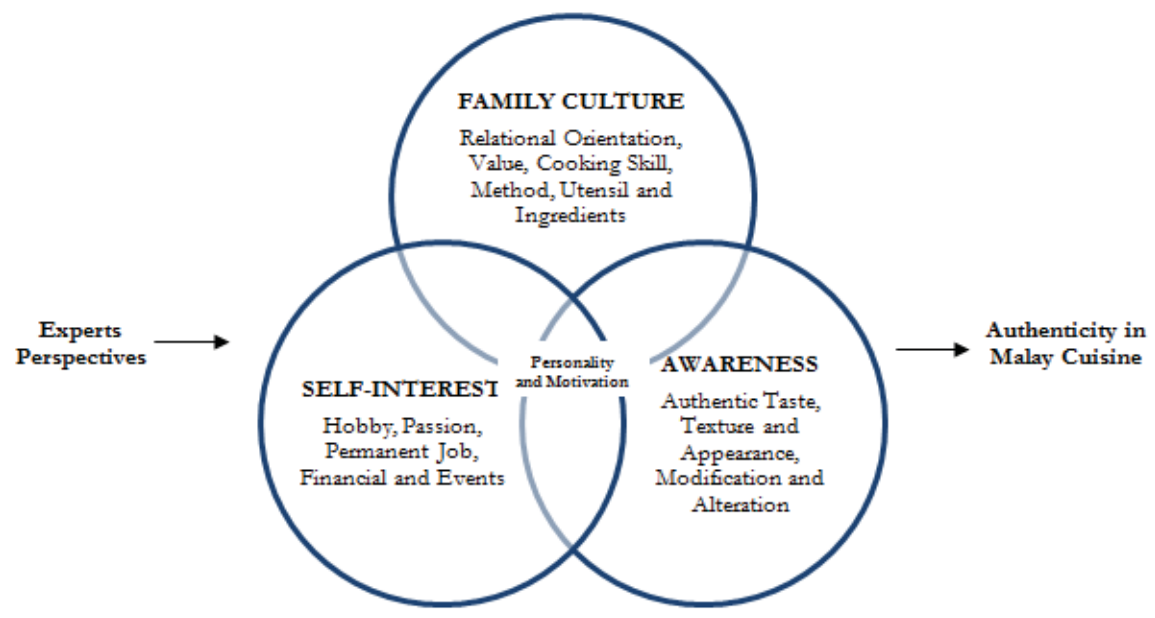

\subsection{Study limitations}

The discussion of the results and implications needs to be accompanied by limitations of the study, which may indicate future improvements and directions. One such limitation is to measures authenticity in Malay cuisines perspectives, due to lack of consensus on definitions. The managerial perspective and parsimony imperative resulted in a relatively limited number of variables and concepts being included in this study. However, the literature review and discussion of the findings indicate that several additional indicators of authenticity in Malay cuisines and need to be considered in the future, such as on sustainability. Although the lead investigator engaged in extensive participant observation and had direct and multiple contacts with most of the experts' members, only a few members are willing to be interviewed. To better understand the relationship between food experts, cultural transmission, and consumers, it is important to examine these dimensions of authenticity in Malay cuisine. The processes of cultural change demonstrated through the types of cuisine remain relevant and are a contribution to the existing culture and authenticity literature. Future studies should include more representative samples from other ethnic and the use of multiple respondents (Shoham \& Dalakas, 2005) such as look from customer perspectives and triangulation with other ethnic. It is also suggested that personal identity and social identity are two ends of a continuum with opposite effects on a same consequence (Terry \& Hogg, 1996). Therefore, a study combining a range of identities might be interesting.

\section{Conclusion}

In conclusion the dimensions of authenticity in Malay cuisine not just as measures from the expert's perspectives alone but through the demand from the consumers to sustain the heritage and the cuisines. While research suggests that a diverse range of relations are expressed when individual make claims about authenticity, few studies address how these interactions unfold and influence the culture. It is related to the family culture, self-interest and awareness of the individual. Although experts have the tendency to sustain the authenticity of the cuisine but on the other hand customer demands become constrain and encourage them to infuse the cuisine with more fusion touch. However they still try to maintain on the taste of the cuisine despite the changing of the cooking method due to the globalization and transformation not mentioning the effect of modernization in changing the eating culture such as the usage of fork and 
spoon instead of eating by using fingers. On the other hand practitioners take pride in the preservation of recipes handed down for generations. The larger culinary culture remains importantly an oral culture, and recipes, when they exist in written form, tend to be imprecise, serving more to jog memory than offer instruction. The evolution of the experts across the magnificent transitions has led to an exponentially growing built environment that, along with its cuisine is unsustainable. These authentic Malay cuisines have not only transformed nature and culture, but the basic structures of the experts towards their personality and motivation to appreciate the authenticity of the cuisines. If care is not taken by the experts and practitioners, a society or the ethnic group can become culturally poor. If measures are not taken, the past will be lost. By identify the dimensions of authenticity and highlight the factors, it will help them and other on how important to sustain our heritage. As a result, researcher will pay close attention to the social conditions under which such assertions the terms of representation and contribute to the sustaining the cuisine in everyday life.

"....for me, you must practice... without practice is nothing to be claim authentic because authentic Malay cuisine is the 'very best' and cannot be change... but as you know food is more forgiving compare to traditional clothes...are agreed with me?". (Participant 8)

\section{Acknowledgements}

This research is fully funded by Research Universiti Grant. The author would like to thank for the full support received from the Universiti Research Grant, Universiti Putra Malaysia. Thank you to the Department of Foodservice \& Management of the Faculty of Food Science and Technology for your assistance.

\section{References}

Ajzen, I. (1991). Organizational Behavior and Human Decision Processes. Theories of Cognitive Self-Regulation, Elsevier, 50(2), 179211.

Ankli, R. E., \& Palliam, R. (2012). Enabling a motivated workforce: exploring the sources of motivation. Development and Learning in Organization, Emerald, 26(2) , 7-10.

Ary, A.H., Anderson, A., \& Hallas, R. (2002). Opposing clines for high and low temperature resistance in Drosophila melanagaster. Ecology Letters, 5:5, pp. 614-618.

Auerbach, C. F., \& Silverstein, L. B. (2003). Qualitative data: An introduction to coding and analysis. New York: New York University Press.

Beer, S. (2008). Authenticity and food experience - commercial and academic perspectives. Journal of Foodservice, 19:3, pp. 153-163.

Bogdwic, S. P. (1999). Participant observation. In B. F. Crabtree \& W. L. Miller (Eds.). Doing qualitative research (2nd ed.). Thousand Oaks, CA: Sage Publications.

Bordens, K.S., \& Abbott, B.B. (2005). Research design and methods: A process approach (6 $6^{\text {th }}$ ed.). Boston:McGraw-Hill.

Bowen, R. L., \& Devine, C. M. (2011). "Watching a person who knows how to cook, you'll learn a lot". Linked lives, cultural transmission, and the food choices of Puerto Rican girls. Appetite , 290-298.

Boyatzis, R. E. (1998). Transforming qualitative information: Thematic analysis and code development. Thousand Oaks, CA: Sage Publications.

Brislin, R. W. (1970). Back-translation for cross-cultural research. Journal of Cross-Cultural Psychology , 1, 185-216.

Caprio, S., Daniels, S. R., Drewnowski, A., Kaufman, F. R., Palinkas, L. A., Rosenbloom, A. L., et al. (2008). Influence of Race, Ethnicity, and Culture on Childhood Obesity: Implications for Prevention and Treatment. Diabetes Care, Vol. 31 (11) 2211-2221.

Carroll, G. R. \& Torfason, M.T. (2011). Restaurant Organizational Forms and Community in the U.S. in 2005. City and Community, 10:1, pp.1-24.

Cohen, E. (1988). Authenticity and commoditization in tourism. Annals of Tourism Research, 15(3) , 371-314.

Comas, D., Calafell, F., Mateu, E., Perez-Lezaun, A., \& Bosch, E. (1998). Trading genes along the silk road: mtDNA sequences and the origin of centrat Asian populations. Am J Hum Genet 63, 1824-1838.

Deci, E. L., \& Ryan, R. M. (1985). Intrinsic motivation and self-determination in human behavior. New York: Plenum.

Deci, E. L., \& Ryan, R. M. (1991). A motivational approach to self: Integration in personality. In R. Dienstbier (Ed.), Nebraska symposium on motivation: Perspectives on motivation (pp. 237-288). Lincoln: University of Nebraska Press.

Eertmans, A., Baeyens, F., \& Van den Bergh, O. (2001). Food likes and their relative importance in human eating behavior: review and preliminary suggestions for health promotion. Health Education Research , 16(4) 443-456.

Fereday, J., \& Muir-Cochrane, E. (2006). Demonstrating Rigor Using Thematic Analysis: A Hybrid Approach of Inductive and Deductive Coding and Theme Development. International Journal of Qualitative Methods, 5(1), 80-91.

Foxman, E.R., Tansuhaj, P.S., \& Ekstrom, K.M. (1989). Family Members' Perceptions in Adolescents' Influence in Family Decision Making. Journal of Consumer Research. 15:4.

Gagne, M., \& Deci, E. L. (2005). Self-determination theory and work motivation. Journal of Organization Behavior, 26 , 331-362.

Graveter, F. J., \& Forzano, L. A. (2008). Research methods for the behavioural sciences. Cengage Learning EMEA, International 
Editions 3e. UK: Gardners Books.

Guerrero, L., Claret, A., Verbeke, W., Enderli, G., Zakowska-Biemans, S., Vanhonacker, F., et al. (2010). Perception of traditional food products in six European regions using free word association. Elsevier , 225-233.

Hatin, W. I., Ab Rajab, N. S., Zahri, M. K., Xu, S., Jin, L., Tan, S.-G., et al. (2011). Population Genetic Structure of Peninsular Malaysia Malay Sub-Ethnic Groups. PLos one, Vol 6(4).

Hughes, G. (1995). "Authenticity in Tourism." Annals of Tourism Research. 20: 197-215

Cairns, K., Johnston, J., \& Szabo, M., (2010) Caring About Food Doing Gender in the Foodie Kitchen. Gender and Society, 24:5, pp. 591-615.

Kolar, T., \& Zabkar, V. (2010). A consumer-based model of authenticity: An oxymoron or the foundation of cultural heritage marketing? Tourism Management, 652-664.

Kuznesof, S., Tregear, A., \& Moxey, (1997). Regional foods: a consumer perspective. British Food Journal, 99:6, pp. $199-206$.

Leigh, T. W., Peters, C., \& Shelton, J. (2006). The consumer quest for authenticity: the multiplicity of meanings within the MG subculture of consumption. Journal of the Academy of Marketing Science, 34(4) , 481-493.

Lu, S. \& Fine, G.A. (1995). THE PRESENTATION OF ETHNIC AUTHENTICITY:

Chinese Food as a Social Accomplishment. The Sociological Quarterly, 36:3, pp.535-553.

Lumeng, J.C. \& Cardinal, T.M. (2007). Providing Information about a Flavour to Preschoolers: Effects on Liking and Memory for Having Tasted It. Oxford Journal, 32:6, pp. 505-513.

Lincoln, Y. A. \& Guba, E. G. (1985). Naturalistic inquiry. Beverly Hills, CA: Sage Publications.

Malaysia Statistic Department (2010)

Maneesriwongul, W., \& Dixon, J. K. (2004). Instrument translation process: A methods review. Journal of advanced Nursing , 48, 175186.

Mason, J (2002). Qualitative researching. London:Sage.

Md. Nor, N., Md. Sharif, M. S., Mohd Zahari, M. S., Mohd Salleh, H., Isha, N., \& Muhammad, R. (2012). The Transmission Modes of Malay Traditional Food Knowledge within Generations. Social and Behavioral Sciences, 50 , 79-88.

Naoi, T. (2004). Visitors' evaluation od a historical district: the roles of authenticity and manipulation. Tourism and Hospitality Research, $5(1), 45-63$.

Olsen, K. H. (2002). Authenticity as a concept in tourism research: the social organization of the experience of authenticity. Tourist Studies, 2(2) , 159.

Olsen, S. O. \& Ruiz, S. (2008). Adolescents' influence in family meal decisions. Appetite, Elsevier, 50(3), pp. 646-653.

Peterson, R. A. (2005). Search of authenticity. Journal of Management Studies, 42(5) , 1083-1098.

Powell, J. (2007). Immigration. New York: Thomas Woll.

Reisinger, Y., \& Steiner, C. J. (2006). Reconceptualizing object authenticity. Annals of Tourism Research, 33(1) , 65-86.

Salleh, H. (2006). The Encyclopedia of Malaysia: People and Traditions (Volume Editor). Kuala Lumpur: Editions Didier Millet.

Schmitt, N. (1998). Quantifying word association responses: What is native-like? System , 26(3), 389-401.

Shoham, A. \& Dalakas, V. (2005). He said, she said ... they said: parents' and children's assessment of children's influence on family consumption decisions. Journal of Consumer Marketing, 22:3, pp. 152-160.

Strauss, A., \& Corbin, J. (1998). Basic of qualitative research: Techniques and procedures for developing grounded theory (2 ${ }^{\text {nd }}$ ed.). Thousand Oaks, CA: Sage Publications.

Terry, D.J. \& Hogg, M.A. (1996). Group Norms and the Attitute-Behavior Relationship: A Role for Group Identification. Personality and Social Psychology Bulletin, 22:8, pp.776-793.

Tuchman \& Levine, H.G. (1992). "New York Jews and Chinese Food: The Social Construction of an Ethnic Pattern". Contemporary Ethnography, 22:3, pp. 382-407.

Tuu, H.H., Olsen, S.O., Thao, D.T., \& Kim Anh, T.N. (2008). The role of norms in explaining attitudes, intention and consumption of a common food (fish) in Vietnam. Appetite, Elsevier, 50(3), pp. 546-551.

UNESCO (2001)a. 'Report on the preliminary study on the advisability of regulating internationally .... the protection of traditional culture and folklore'. http://unesdoc.unesco.org/images/0012/001225/122585e.pdf.

Varadachari, S. (2002). The science of creating a memorable flavor. American Association of Cereal Chemists, 47:3, pp.84-86.

Verbeke, W., \& Lopez, G. (2005). A Longitudinal Application of the Theoty of Reasoned action to Women's Career Behavior. British Food Journal, 107(11) , 832-840.

Vu, V. (2009). The Changing Foodways of Vietnamese Americans in Orange County, California. Carlifornia: Carlifornia University.

Wellen, Jackie M.; Hogg, Michael A.; Terry, Deborah J (1998).Group norms and attitude-behavior consistency: The role of group salience and mood. Theory, Research, and Practice, 2:1, pp. 48-56.

Yeoman, I. S., Brass, D., \& Mcmohan-Beattie, U. (2007). Current issue in tourism: the authentic tourist. Annals of Tourism Research, 28(4) , 1128-1138. 
